\title{
A perversão enquanto estrutura e sua incidência na transferência
}

\author{
Felipe Lima Baségio, ${ }^{\star}$ Norton Cezar Dal Follo da Rosa Junior \\ Universidade Feevale, Novo Hamburgo, RS, Brasil \\ Universidade Federal do Rio Grande do Sul, Porto Alegre, RS, Brasil
}

\begin{abstract}
Resumo
O artigo aborda o conceito de estrutura perversa a partir das elaborações de Freud e Lacan. Utiliza-se um caso clínico visando a problematizar a especificidade da transferência em questão. A partir dessa experiência, colocam-se em discussão os impasses e as possibilidades no que diz respeito à direção de tratamento psicanalítico. No tratamento em questão, ressalta-se a importância de o analista não se mostrar chocado com o que escuta, condição necessária para ler a posição do sujeito em relação a pulsão. Pensar essas questões torna-se relevante na atualidade, pois a perversão é um tema polêmico e complexo, inclusive dentro do campo psicanalítico.
\end{abstract}

Palavras-chave: perversão; estrutura; transferência; Freud; Lacan.

\section{The perversion as structure and its impact on transfer}

\begin{abstract}
The article discusses the concept of perverse structure, based on Freud's and Lacan's elaborations. A clinical case is used to problematize the specificity of the transfer in question. From this experience, the impasses and possibilities concerning the direction of psychoanalytic treatment are discussed. In the mentioned treatment, it is emphasized that is important the analyst not to show that he is shocked by what he listen to, being this a necessary condition to read the position of the subject in relation to the drive. Thinking about these issues becomes relevant today, because perversion is a controversial and complex subject, even within the psychoanalytic field.
\end{abstract}

Keywords: perversion; structure; transference; Freud; Lacan.

\section{Introdução}

O presente artigo surge a partir da experiência de um caso clínico. Tem-se como objetivo problematizar a lógica referente à ideia de estrutura perversa e suas incidências na especificidade da transferência no campo da perversão. Isso dará condições para problematizar os impasses e as possibilidades no que diz respeito à direção de tratamento psicanalítico. Para que se possa avançar nessas interrogações, propõe-se tomar como referência algumas elaborações de Freud e de Lacan sobre essa temática. Além disso, dialogar com construções de psicanalistas contemporâneos.

Pensar essas questões torna-se relevante na atualidade, pois a perversão é um tema polêmico e complexo, inclusive dentro do campo psicanalítico. Mais ainda, ao se estabelecer um comparativo com a literatura psicanalítica sobre o tema das neuroses e perversões, pode-se dizer que há, até o presente, pouca produção teórica em torno da perversão.

Inicialmente, propomos uma breve apresentação de um caso clínico, com o propósito de fazer uma articulação teórica em que se utilizam alguns recortes de leitura da transferência em questão.

Ronaldo, quando procurou tratamento, tinha 28 anos. Chegou a um serviço de atendimento solicitando um psicólogo urgente, mesmo que isso implicasse passar na frente de outros que aguardavam na fila de espera. Uma profissional da equipe fez o acolhimento do caso e logo

\footnotetext{
^Endereço para correspondência: Universidade Feevale, Câmpus II. ERS-239, 2755. Novo Hamburgo, RS - CEP: 93525-075. E-mail: fbasegio@gmail.com, nortonjr@brturbo.com.br
}

após levou-o ao conhecimento do restante da equipe. Em seu relato do caso, disse ter ficado assustada, pois o sujeito, durante a entrevista, deixou-a sensivelmente constrangida.

Quanto ao procedimento de acolhimento, cabe observar que este se caracteriza por uma entrevista inicial, em que se verifica a demanda e para qual especialidade o caso deverá ser direcionado. Após esse encaminhamento, o caso é levado para a equipe e discutido, definindo-se quem prosseguirá com o tratamento.

Durante a entrevista de acolhimento, Ronaldo teria referido problemas de relacionamento com as pessoas, pois sofria de "fobia social". Porém, o que realmente deixou a profissional preocupada nessa ocasião foi $o$ fato de ele ter ficado olhando para ela como um tarado, deixando-a desestabilizada. Isso, inclusive, levou-a a supor que pedir para ir ao banheiro e retornar com o zíper da calça aberto teria sido um ato intencional de Ronaldo, com o objetivo de constrangê-la.

Após a discussão do caso em equipe, o recebi para tratamento. Ele mencionou a existência de diversos problemas: a timidez, materializada na dificuldade de relacionamento com as pessoas, dizendo não saber o que conversar; exibição na rua, mostrando seu pênis para mulheres, não importando a idade. Além disso, mencionou que não se contentava em ficar se exibindo, pois tinha vontade de agarrá-las à força, chegando inclusive a espancá-las.

No andamento do tratamento lembrava-se de atos que cometia com as mulheres na rua (como masturbar-se e ejacular na calça de uma mulher que estava numa parada de ônibus). Tendo em vista a complexidade das questões com que estávamos nos deparando e, sobretudo, a dificuldade 
inicial de pensar na especificidade da transferência endereçada ao lugar do analista, num primeiro momento, ficou-se em dúvida em função de qual a especificidade da estrutura em questão nesse caso: psicose ou perversão?

\section{A noção de estrutura e sua incidência no diagnóstico}

A interrogação de uma estrutura é importante na condução de um caso clínico, pois, como ressalta Freud (1913/1996) em Sobre o início do tratamento, há uma dificuldade de se fazer o diagnóstico diferencial. Se for feito de forma errônea, traz grandes prejuízos para o tratamento, uma vez que incide na prática, na condução do caso, tendo efeitos nocivos, além de despertar uma violenta oposição no paciente. Percebendo-se a importância do diagnóstico, traz-se a contribuição de Martinho (2011), pois segundo a autora um cenário de gozo e condutas perversas não deve ser suficiente para se diagnosticar um sujeito perverso.

Diagnosticar um sujeito perverso é bem mais sutil do que apenas dizer que basta um cenário de gozo perverso para que se esteja diante de um perverso. Não se deve definir uma estrutura a nível da fenomenologia dos sintomas nem tampouco das condutas, ou seja, daquilo que é observável, haja vista o fato de que encontramos, por exemplo, manifestações aparentemente obsessivas na psicose (MARTINHO, 2011, p. 138).

Com essa citação, mostra-se a necessidade de diferenciar perversão enquanto estrutura, pois, na neurose, é possível ter uma "montagem perversa" e saídas perversas em algumas situações, tornando-a diferente da perversão. Neste sentido, há uma especificidade da questão diagnóstica em psicanálise, pois de certo modo implica numa certa subversão da sintomatologia e suas variantes comportamentais, para que o analista possa ler a posição do sujeito no discurso e sua relação com o saber. Isto será uma espécie de condição preliminar para que se possa esboçar uma hipótese diagnóstica. Do contrário, corre-se o risco de a escuta ser capturada pela fenomenologia. Ainda em relação à estrutura, a autora refere que:

Uma estrutura clínica deve ser definida na relação entre o \$ (efeito de linguagem) e o Outro (que inclui o inconsciente), por isso é preciso saber como a relação fantasmática entre o sujeito e o Outro se apresenta. Deve-se identificar como o cenário de gozo na fantasia se coloca em relação ao desejo inconsciente (MARTINHO, 2011, p. 138).

Problematizando-se a noção de uma estrutura perversa, um caminho possível para avançar na questão pode ser a posição do sujeito em relação à fantasia. Se, pelo lado das pulsões, o voyeurismo-exibicionismo são dissimétricos, na fantasia, são paralelos, segundo Lacan (19581959/2016). Nesse sentido, Lacan (1958-1959/2016), em seu Seminário, livro 6: O desejo e sua interpretação, diz que o exibicionista está indicado por uma hiância, algo que é, ao mesmo tempo, buraco e clarão.

Ao contrário, paradoxalmente, essas duas posições são rigorosamente paralelas. Em ambos os casos, o sujeito é indicado na fantasia pelo que chamamos de "fenda", de hiância, algo que, no real, é ao mesmo tempo buraco e lampejo, na medida em que o voyeur espia por trás de sua persiana, que o exibicionista entreabre seu anteparo. Que ele está aí indicado em seu lugar no ato; que ele não é nada além do que esse clarão. Aqui, o sujeito é indicado pelo seu lugar no ato. Ele nada mais é que esse lampejo do objeto a que nos referimos e que é vivido, percebido, pelo sujeito como a abertura de uma hiância que, por sua vez, o situa como aberto. Aberto para quê? Para outro desejo que não o seu, estando seu desejo profundamente afetado, atingido, abalado, pelo que é percebido no lampejo (LACAN 1958-1959/2016, p. 453).

Outro aspecto importante para pensar a estrutura diz respeito à posição do sujeito em relação ao saber. Para Calligaris (1986) essa forma está relacionada com a estrutura psíquica. $\mathrm{Na}$ neurose, esse saber está no Outro, coloca o suposto saber no analista; na psicose, há uma certeza desse saber, ao passo que, na perversão, segundo o autor, o perverso pensa ter este saber, goza na busca da detenção desse saber, por isso se faz instrumento do gozo do Outro.

Se este saber, que permite ter o domínio do gozo do Outro, eu próprio o tenho, não se trata de o supor a um suposto sujeito; então posso realizar o fantasma - já que agora é sem perigo, já que tenho o saber que domina este gozo e também sei como utilizar o objeto para fazer o outro gozar. Por isso esse objeto se torna um interessante instrumento: meu ser objetável se torna tolerável porque eu tenho o domínio de seu uso. Por isso o perverso torna-se, ao mesmo tempo, o objeto que virou instrumento, e o sujeito do saber sobre o bom uso desse instrumento (CALLIGARIS, 1986, p. 12).

Pensando no caso de Ronaldo, ele afirma que as mulheres para quem ele se exibe gostam de ver, como se dissesse: "elas gozam também". A partir de Lacan (19681969/2008) pode-se interrogar o quanto essa afirmação situa a posição do perverso em relação ao saber, ou seja, supor deter o saber sobre o gozo do Outro. Logo, ele não demanda o saber, como o neurótico - ele sabe.

Coutinho et al. (2004) refere que, enquanto na neurose o sujeito se questiona a respeito do seu desejo - que quero? -, na perversão, existe uma resposta sobre o desejo.

$\mathrm{Na}$ perversão, o desejo aparece como vontade de gozo e o ato é vivenciado como vitorioso triunfo isento de qualquer sentimento de culpa. O perverso sabe o que quer e isto é a base da sua arrogância, já que está convencido de saber a verdade sobre o gozo (COUTINHO et al., 2004, p. 20).

Desse ponto de vista, as construções realizadas por Calligaris e Coutinho parecem estar em sintonia com as elaborações de Lacan (1968-1969/2008) no Seminário De um Outro ao outro. Neste, o psicanalista refere que o perverso é aquele que se consagra em tapar o buraco no Outro. A experiência de escuta clínica com Ronaldo fez pensar na busca de um sujeito por um gozo sem falhas, ininterrupto. Isso leva a supor que a questão fundamental no que diz respeito à ideia de estrutura e, consequentemente, de diagnóstico em psicanálise é a posição do sujeito frente à castração.

Por vezes, Ronaldo trouxe cenas da infância, em que tentava espiar por baixo da saia de uma menina. Ao relatar a cena, falou: "não via nada". Contou outra 
cena, em que estava espiando a mesma menina tomando banho: "ela estava de frente, não me lembro de ver nada. Talvez eu tenha visto os seios, mas não vi mais nada".

Isso levou a questionar acerca do que era esse nada que ele (não) viu? Em relação à cena, pode-se perceber que se trata de uma cena comum na infância: a curiosidade de um pequenino em relação ao seu próximo, mais precisamente, a curiosidade em relação à diferenciação sexual. Porém, no momento em que se depara com a falta na menina, Ronaldo diz não ter visto nada. Esta fala nos leva a questionar se esse nada poderia ser uma maneira, encontrada pelo sujeito para negar a diferenciação sexual?

Em relação à castração, Martinho (2011) traz que o sujeito perverso faz do outro sua vítima para restituir o objeto faltante, desmentindo que o Outro seja castrado, ou seja, faz do outro sua vítima para apontar a sua castração e ao mesmo tempo desmentir a castração do Outro.

Em seu ato perverso o sujeito faz do outro sua vítima restituindo o objeto que falta para desmentir que o Outro seja castrado, restituindo o gozo do Outro. E é justo nesse "ponto" que podemos encontrar uma diferença radical entre a neurose e a perversão - a posição do sujeito frente ao gozo (MARTINHO, 2011, p. 139).

\section{Exibicionismo}

A partir das questões até aqui analisadas, é possível pensar que, no caso de Ronaldo, se trata de um caso de exibicionismo que nos leva a formular uma hipótese de perversão. Como consequência dessa hipótese, torna-se necessário explorar o entendimento desse conceito pela psicanálise.

O que busca o exibicionista é o olhar do Outro, ainda que isso requeira o pudor do outro, pelo qual o exibicionista não se sente culpado e, muito menos, envergonhado. Há uma cena relatada por Ronaldo em que ele diz:

[...] estava no meu quarto e vi uma menina na janela da frente. Tiro a calça e fico só de cueca. A menina devia ter uns 10 anos [...] Ela escreveu numa folha grande, pedindo que eu mostrasse o pinto, sei lá, escreveu do jeito dela; me senti usado naquele momento e fechei a janela.

Essa cena mostra que, quando a menina não demonstrou vergonha, pudor, Ronaldo recuou. Por que isso teria ocorrido? Nossa hipótese é de que o seu gozo está em apontar a castração do outro; então, se ela não ficou constrangida, ele fracassou em atingir o pudor dela.

Outra questão relevante dentro do exibicionismo é poder diferenciá-lo do voyeurismo. Para Lacan, uma pulsão não é o retorno de outra, como pensava Freud (1915/1996) em O instinto e suas vicissitudes. Lacan (1968-1969/2008, p. 246) fala que, no caso do voyeurismoexibicionismo, as pulsões são dissimétricas e "[...] ainda que o essencial aqui é a função de um suplemento, de algo que, no nível do Outro, interroga o que falta no Outro como tal e se previne contra isso". Para esse autor, é no campo do Outro que o exibicionista se coloca - o Outro estaria desertado pelo gozo - para fazer surgir ali o olhar, que é assimétrico ao do voyeur, que busca justamente interrogar no Outro o que não se pode ver.

Lacan (1968-1969/2008) refere que as pessoas se indagam sobre os efeitos da exibição no outro - se causa medo, se provoca o pudor, um susto? Diz que isso não é o essencial da pulsão escopofílica. "O essencial, propriamente e antes de mais nada, é fazer aparecer o olhar no campo do Outro" (LACAN, 1968-1969/2008, p. 246). Ele segue, dizendo: "é pelo gozo do Outro que o exibicionista zela" (LACAN, 1968-1969/2008, p. 246). Se, de um lado, Lacan vai afirmar que o exibicionista goza, de outro, vai dizer que o gozo de que se trata é o gozo do Outro, pois, nesse caso, o gozo surge como uma tentativa de tamponar a falta, como uma espécie de busca do objeto que faça isso. Isso leva a pensar que, em relação à pulsão escopofílica, há um que tem êxito no fazer gozar o Outro e um que está ali para tapar o buraco com seu próprio olhar. Assim, questiona-se o sentido do ato de ver e de dar a ver. Em resposta a essa dúvida, Lacan (1956-1957/1995) diz haver no exibicionismo um mostrar o que ele tem, na medida em que o outro não tem, mergulhando-o na vergonha daquilo que lhe falta.

É assim que, num grau superior ao ver e ser visto, a dialética imaginária resulta num dar-a-ver e ser surpreendido pelo desvelamento. [...] A técnica do ato de exibir consiste, para o sujeito, em mostrar o que ele tem, precisamente na medida em que o outro não tem (LACAN, 1956-1957/1995, p. 277).

Faz-se necessário perceber que existem diversas questões no exibicionismo, porém, é importante atentar que não é somente a questão do olhar que está em pauta. Lacan, ao longo de sua obra, diz que não é possível tomar a questão do exibicionismo-voyeurismo pela simples relação entre aquele que vê e aquele que se mostra.

O que está em questão, tanto na fantasia do exibicionista como na do voyeur, é um elemento terceiro, que implica que pode surgir no parceiro uma consciência cúmplice que recebe o que lhe é dado ver - que aquilo que o expande em sua solidão, aparentemente inocente, se oferece a um olhar oculto - que, assim, e o próprio desejo que sustenta sua função na fantasia, que vela para o sujeito seu papel no ato - que o exibicionista e o voyeur gozem, de alguma maneira, vendo e mostrando, mas sem saberem o que veem e o que mostram (LACAN, 1960-1961/1992, p. 300).

\section{Transferência}

A transferência é um ponto nodal na clínica, pois, através dela, também é possível pensar na estrutura em questão.

Existem psicanalistas que se questionam se perversos procuram análise; caso procurem, se acontece de fato uma análise, se eles mantêm o tratamento por muito tempo e se é possível estabelecer transferência na perversão. Entretanto, para Pommier (1998), perversos procuram analistas e, se o fazem, é porque há um endereçamento e, sendo assim, uma transferência potencial. O autor acrescenta que, estando o sujeito na linguagem, há uma transferência e a questão é examiná-la em cada uma das três estruturas propostas pela psicanálise. 
A partir do assujeitamento de todo ser humano à palavra, define-se uma transferência de toda forma obrigatória, porque ninguém pensa sem palavras que sejam partilhadas, transferidas. Uma vez admitida esta generalidade, é um outro problema examinar o que se torna esta transferência na psicose, na neurose ou na perversão. $O$ amor de transferência permite questionar e ordenar a clínica, não o contrário (POMMIER, 1998, p. 12).

A partir dessas discussões, as questões que surgem são: em que posição o perverso coloca o analista? O que busca deste?

Pensa-se ser importante recorrer à clínica novamente, possibilitando um melhor entendimento das questões de transferência. Através de uma cena que situa as possibilidades de Ronaldo colocar em ato a sua fantasia e sendo assim, nos ajuda a avançar nestas interrogações. Após sair de uma sessão, o analisante ficou na sala de espera e mostrou o pênis para uma mulher que ali aguardava. Isso nos levou a supor uma tentativa dele de colocar o analista como cúmplice de seu ato. Essa atuação fez pensar que, além do desafio, de alguma forma ele estava confrontando o analista, com o intuito de ver até que ponto ele suportava o horror de seu ato ou até mesmo se ele estaria disposto a manter a condução do tratamento. Diante de tal situação, optou-se por uma intervenção na sessão seguinte a este episódio, afirmando-se que não seria permitido que aquilo acontecesse novamente naquele local de trabalho. Caso contrário, haveria a suspensão do tratamento. Isso se deu em função da necessidade de deixar clara uma interdição, ou seja, que naquele local não eram possíveis tais atuações. Logo após, o analisante disse achar que não haveria possibilidade de melhora, inclusive questionando se o analista já havia trabalhado com casos difíceis assim, como o dele.

Isso levou a pensar que houve uma tentativa de Ronaldo de inverter a situação, não reconhecendo a colocação feita pelo analista e tirando o foco do ato que cometeu, para interrogar a capacidade do analista que o escutava. Porém, esse comportamento, como visto até então, isoladamente, não determinava uma perversão, já que, em raras exceções, neuróticos também podem realizar esse tipo de saída perversa. A análise desse sujeito levou ao questionamento sobre a origem de um eventual sofrimento na perversão.

Concordamos com Pommier (1998) que, se existe um sofrimento no perverso, pode dar-se como um momento de angústia que emerge quando o sujeito se depara com o outro. Com esse sofrimento fazendo parte do gozo, não se deveria receber um perverso? Segundo o autor, muitos psicanalistas acreditam ser apenas uma forma de atingir um gozo transgressivo, "onde a cura só constitui um exutório suplementar” (POMMIER, 1998, p. 443). O risco existe - o analista é passível de ser manipulado. Pensando bem, percebe-se que os neuróticos também fazem essa tentativa, de outras formas, mas tentam. "E nenhuma análise pode começar se o analista não aceita cair na armadilha desta demanda, se ele não faz o pato até um certo ponto" (POMMIER, 1998, p. 443).
Ronaldo acolheu em sua literalidade a regra de dizer tudo o que vem à cabeça. Não houve momentos em que ele deixasse de dizer algo; pelo contrário, contava tudo nos mínimos detalhes, como que buscando produzir alguma espécie de repulsa no analista. De outro lado, também foi possível escutar que havia angústia. O analisante foi buscar tratamento pela sua timidez frente ao outro, por não saber o que falar e quando falar. Isso parecia angustiá-lo, mas havia concomitante, a busca pelo gozo transgressivo.

Para ajudarmos a interrogar esta questão relata-se aqui outra cena. Ronaldo havia parado com seu tratamento, alegando não conseguir pagar mais os atendimentos, o que o deixou com uma dívida de algumas sessões. Combinouse que ele viria pagar para retomar sua análise. Certo dia foi realizar o pagamento, porém, ao sair do consultório, no elevador do prédio, ao invés de ir para o térreo, foi para os andares superiores, olhou algumas mulheres e voltou se masturbando no elevador, onde o síndico o encontrou, resolvendo chamar a polícia. Quando a polícia apareceu, ele disse ser paciente de um profissional no prédio, o que fez com que a polícia quisesse confirmar a informação com o analista. Esse exemplo é citado para mostrar como ele descumpriu a regra de que aqueles atos não poderiam se repetir naquele local de trabalho e como, de certa forma, ele quis fazer o analista pagar também. No momento em que a polícia o levava, Ronaldo olhou para o analista e perguntou: "vamos poder continuar $o$ tratamento?". O analista respondeu que iriam conversar sobre isso na próxima sessão. $\mathrm{O}$ analisante não retornou.

A transferência também aparece como instrumento de gozo, pois o perverso não terá pudor algum em revelar os detalhes de sua vida íntima, que serão enunciados com o propósito repugnante de desestabilizar o analista. Segundo Pommier (1998), o analisando de estrutura perversa não terá pudor em acolher, rapidamente, a regra analítica de dizer tudo que lhe vem à cabeça, buscando assim produzir o nojo naquele que é pago para ouvir. Nesse associar livremente, hesitações e tropeços de linguagem raramente ocorrem.

Procurou-se trazer cenas do tratamento para demonstrar algumas das incidências na transferência ao tomar-se em análise um sujeito cuja estrutura é perversa. Isso faz questionar a direção do tratamento, pois se supõe que haja minimamente uma possibilidade de estabelecimento de transferência, até porque, como diz Lacan, "mostra-se para agredir o outro, sem dúvida, mas o que não se deve esquecer é que o exibicionista está convencido de que essa agressão é uma fonte de gozo, para o Outro" (LACAN, 1961-1962/2003, p. 288).

\section{Gozo}

A experiência de escuta com esse caso permitiu considerar importante ater-se um pouco mais a esse conceito crucial na psicanálise que é o gozo.

Lacan, em 1969, no seminário intitulado De um Outro ao outro, desenvolve o seguinte conceito de gozo:

Essa centralidade é o que designo como o campo do gozo, definindo-se o gozo em si como tudo o que decorre da 
distribuição do prazer no corpo. Essa distribuição, seu limite íntimo, é isso que condiciona o que numa certa época, e com mais palavras e mais ilustrações, é claro do que posso usar aqui, designei como o vacúolo - a proibição no centro que, em síntese, constitui o que nos é mais próximo, embora nos seja externo. Seria preciso criar a palavra êxtimo* para designar aquilo de que se trata (LACAN, 1968-1969/2008, p. 218, grifo do autor).

Lacan (1968-1969/2008) diz que o gozo é definido como tudo que decorre da distribuição do prazer no corpo, sendo assim, deve-se perguntar: que parte do corpo goza? Nesse caso, pensa-se tratar do olhar, este olhar que o exibicionista busca, exibindo-se. Pode-se dizer mais, que o exibicionista busca o olhar do Outro. Lacan diz que o gozo está ligado ao Outro Primordial, pois ele será efeito do Outro sobre o sujeito. Logo, para gozar, o sujeito deve primeiro ter estado no lugar de objeto - objeto do desejo de alguém.

Há uma passagem no Seminário, livro 16: De um Outro ao outro, onde Lacan (1968-1969/2008, p. 74) diz:

A mulher permite ao gozo ousar a máscara da repetição. Ela aqui se apresenta como o que é, como instituição da mascarada. Ela ensina seu pequeno a se exibir. Ela conduz ao mais - de - gozar porque mergulha suas raízes, ela, a mulher, como a flor, no gozo mesmo. Os meios de gozo são abertos pelo seguinte princípio - que ele tenha renunciado ao gozo fechado e alheio, à mãe.

Seguindo a proposta de dialogar com a clínica, traremos mais um recorte do caso. $\mathrm{O}$ analisante pouco se lembrava da mãe, pois esta saiu de casa quando ele ainda era bem pequeno, e sendo assim não sabia precisar a idade. Inicialmente, o analisante dizia não querer saber de sua mãe, que não sentia nada por ela, porque sempre viveu com o pai. Entretanto, no decorrer de seu tratamento, começou a questionar-se por que sua mãe os abandonara e também se permitiu falar da raiva que sentia dela. Lembrou que seu pai dizia que sua mãe os tinha abandonado, que ela era uma puta, porque, mesmo enquanto casada, ficava no portão conversando com homens, e que saiu de casa por isso, por não conseguir ficar apenas com um homem. No decorrer do tratamento, Ronaldo associou a raiva que sentia pelas mulheres à raiva que tinha de sua mãe.

É possível pensar que, ao exibir-se, solicitando o olhar das mulheres, o analisante estaria convocando o olhar materno? Este caso nos fez interrogar o circuito pulsional do olhar. Martinho (2011), explicando a questão do olhar, diz que este é o objeto perdido, o olhar da mãe, para o qual a pulsão tenta encontrar objetos substitutos para satisfazer-se, mas o próprio jamais é reencontrado.

Objeto $a$ é produzido cada vez que a pulsão contorna o seu circuito. O olhar é o objeto cortado do corpo do Outro; é o objeto perdido que o sujeito teria um dia encontrado e logo perdido; olhar da mãe, perdido para sempre, e no lugar do qual a pulsão tenta encontrar objetos substitutos para se satisfazer sem jamais reencontrá-lo (MARTINHO, 2011, p. 160).

Fractal, Rev. Psicol., v. 29 - n. 1, p. 65-70, 2017
Martinho (2011), analisando um caso de perversão, diz que, a cada vez que a pulsão escópica completa o seu circuito - olho, me olho, sou olhado -, o olhar se torna presente. Ronaldo fica justamente preso no "sou olhado"; ele se coloca nessa posição para fazer surgir o olhar.

Ainda ficam diversas questões a respeito desse caso: por que ele se sentiu usado? Por que resolveu buscar análise? Por que sustentou por mais de um ano o tratamento? Por que disse querer parar com aqueles atos? Quais as possibilidades de direção de tratamento?

\section{Verleugnung e direção de tratamento}

A discussão sobre o conceito de perversão faz-se indispensável na psicanálise. A seguir, apresenta-se uma possível direção de tratamento.

A Verleugnung, traduzida como recusa ou desmentido, refere-se à castração, ou seja, à recusa da castração. $\mathrm{Na}$ obra de Freud, esse conceito aparece diversas vezes, e esse é o caminho escolhido nesta argumentação.

Primeiramente, o conceito aparece em $A$ organização genital infantil, de 1923, onde Freud cita que a criança recusa a ausência do pênis na mulher. Ele escreve:

Sabemos como as crianças reagem às suas primeiras impressões da ausência de um pênis. Rejeitam o fato e acreditam que elas realmente, ainda assim, veem um pênis. Encobrem a contradição entre a observação e a preconcepção dizendo-se que o pênis ainda é pequeno e ficará maior dentro em pouco, e depois lentamente chegam à conclusão emocionalmente significativa de que, afinal de contas, o pênis pelo menos estivera lá, antes, e fora retirado depois (FREUD, 1923/1996, p. 159).

Em 1924, em A perda da realidade na neurose e na psicose, Freud (1924/1996) traz a ideia da recusa da castração ligada à psicose, ideia que se mantém no artigo Algumas consequências psíquicas da distinção anatômica entre os sexos, de 1925, onde afirma o seguinte: "[...] Ou, ainda, pode estabelecer-se um processo que eu gostaria de chamar de 'rejeição', processo que, na vida mental das crianças, não aparece incomum nem muito perigoso, mas em um adulto significaria o começo de uma psicose" (FREUD, 1925/1996, p. 281).

Freud muda seu entendimento sobre o assunto a partir do Fetichismo, de 1927, quando diferencia a Verleugnung, retirando-a da psicose, considerando que nesta estrutura haveria uma retirada da percepção da realidade, mas na Verleugnung não. Nesta, há uma recusa da castração. Freud (1927/1996, p. 160) escreve:

$\mathrm{Na}$ situação que estamos considerando, pelo contrário, vemos que a percepção continuou e que uma ação muito enérgica foi empreendida para manter a rejeição.

Então, diferentemente da psicose, em que há uma foraclusão do nome-do-pai, na perversão, há uma Verleugnung, ou seja, uma recusa da castração. $\mathrm{Na}$ psicose, não há uma inscrição da castração; na perversão, há a inscrição, há o reconhecimento, mas há uma recusa.

Por fim, faz-se importante citar uma possibilidade de direção de tratamento na clínica com a perversão. Pommier (1998) traz que, na medida do possível, o 
analista não deve mostrar-se chocado com o que ouve. Também deve "evitar deixar-se picar pela curiosidade, por mais extraordinário ou inverossímil que possa parecer o que escuta" (POMMIER, 1998, p. 448).

Outra possibilidade é que o analista atente para a posição do sujeito. Ela deve ser analisada não em sua relação com o sintoma ou com o nome, mas em sua relação com a pulsão. "É ela que o leva a agir anonimamente, sem saber quem é - contrariamente ao que se produz na neurose, onde o sujeito age sem saber o que faz" (POMMIER, 1998, p. 472). Ou seja, é o sujeito da pulsão - o que renega a castração materna - que é ausentado no ato, não o sujeito da fantasia, que busca realizar o desejo.

\section{Referências}

CALligaris, C. Perversão: um laço social? Salvador: Cooperativa Cultural Jacques Lacan, 1986.

COUTINHO, A. H. A. et al. Perversão: uma clínica possível. Revista Reverso, Belo Horizonte, ano 26, n. 51, p. 19-28, dez. 2004. Disponível em: <http://pepsic.bvsalud.org/scielo. php?script=sci_arttext\&pid=S0102-73952004000100003\&lng $=$ pt\&nrm=iso\&tlng=pt>. Acesso em: 23 fev. 2015 .

FREUD, S. Sobre o início do tratamento (1913). In: SALOMÃO, J. (Org.). Obras Psicológicas Completas de Sigmund Freud. Rio de Janeiro: Imago, 1996. v. 12, p. 135-158. Edição Standard Brasileira.

FREUD, S. O instinto e suas vicissitudes (1915). In: SALOMÃO, J. (Org.). Obras Psicológicas Completas de Sigmund Freud. Rio de Janeiro: Imago, 1996. v. 14, p. 117-123. Edição Standard Brasileira.

FREUD, S. A organização genital infantil: uma interpolação na teoria da sexualidade (1923). In: SALOMÃO, J. (Org.). Obras Psicológicas Completas de Sigmund Freud. Rio de Janeiro: Imago, 1996. v. 19, p. 155-161. Edição Standard Brasileira.

FREUD, S. A perda da realidade na neurose e na psicose (1924). In: SALOMÃO, J. (Org.). Obras Psicológicas Completas de Sigmund Freud. Rio de Janeiro: Imago, 1996. v. 19, p. 203-209. Edição Standard Brasileira.

FREUD, S. Algumas consequências psíquicas da distinção anatômica entre os sexos (1925). In: SALOMÃO, J. (Org.). Obras Psicológicas Completas de Sigmund Freud. Rio de Janeiro: Imago, 1996. v. 19, p. 273-286. Edição Standard Brasileira.

FREUD, S. Fetichismo (1927). In: SALOMÃO, J. (Org.). Obras Psicológicas Completas de Sigmund Freud. Rio de Janeiro: Imago, 1996. v. 21, p. 159-164. Edição Standard Brasileira.

LACAN, J. O Seminário: a transferência (1960-1961). Rio de Janeiro: J. Zahar, 1992. livro 4.

LACAN, J. O Seminário: a identificação (1961-1962). Recife: Centro de Estudos Freudiano de Recife, 2003. livro 9. Publicação para circulação interna do Centro de Estudos Freudiano de Recife.

LACAN, J. O Seminário: a relação de objeto (1956-1957). Rio de Janeiro: J. Zahar, 1995. livro 4.

LACAN, J. O Seminário: de um Outro ao outro (1968-1969). Rio de Janeiro: J. Zahar, 2008. livro 16.

LACAN, J. O seminário: o desejo e sua interpretação (19581959). Rio de Janeiro: J. Zahar, 2016. livro 6.
MARTINHO, M. H. C. Perversão: um fazer gozar. 2011. 339 f. Tese (Doutorado em Psicanálise) - Instituto de Psicologia, Universidade do Estado do Rio de Janeiro, Rio de Janeiro, 2011.

POMMIER, G. O amor ao avesso: ensaio sobre a transferência em psicanálise. Rio de Janeiro: Companhia de Freud, 1998.

Recebido em: 22 de março de 2015 Aceito em: 24 de março de 2017 